\title{
Weak Agnosticism Defended ${ }^{1}$
}

Agnosticism has had some bad press in recent years. Nonetheless, I hope to show that agnosticism can be so formulated that it is no less philosophically respectable than theism and atheism. This is not a mere philosophical exercise; for, as it happens, the formulated position is -- I think -- the one to which I subscribe. I include a qualification here since it may be that the position to which I subscribe is better characterised as fallibilist atheism -- but more of that anon.

I begin by distinguishing between two different kinds of agnosticism. On the one hand, there is strong agnosticism, i.e. the view which is sustained by the thesis that it is obligatory for reasonable persons to suspend judgement on the question of God's existence. And, on the other hand, there is weak agnosticism, i.e. the view which is sustained by the thesis that it is permissible for reasonable persons to suspend judgement on the question of God's existence.

Strong agnosticism is characteristically defended by appeal to the apparent lack of good independent evidential support for the claim that God exists. Underlying this appeal there is typically an epistemological principle which resembles the following: in circumstances in which the available evidence no more -- and no less -- supports $p$ than it supports logically incompatible hypotheses $p_{1}, \ldots, p_{n}, \ldots$, one ought to suspend judgement between all of the hypotheses $p, p_{1}, \ldots, p_{n}, \ldots$. Moreover, also underlying this appeal there is typically a further principle, along the following lines: it is possible to characterise a suitable notion of evidential support which does not rely upon a relativisation to background assumptions or theories. In the next two sections of this paper, I propose: (i) to sketch the best case that I can make for strong agnosticism; and then (ii) to argue that the case fails because the two kinds of principles required for strong agnosticism cannot be plausibly conjoined.

Weak agnosticism is, I think, best defended via an appeal to a principle of epistemic conservatism, along the following lines: one is rationally justified in continuing to believe that $p$ unless one comes to possess positive reason to cease to do so. In the third and fourth sections of this paper, I attempt to make a case for weak agnosticism, and to defend this case against objections. Since the strength of this case depends upon the underlying principle of epistemic conservatism, I shall also provide some assessment of the merits of this kind of approach to epistemology. 
The strong agnostic claims that it is not rational to believe in the existence of the God of traditional Western theism -- i.e. the unique, personal, omniscient, omnipotent, omnibenevolent, eternal creator ex nihilo of the universe. However, unlike some atheists, the strong agnostic does not believe either: (i) that talk of such a God is meaningless or incoherent; or (ii) that the concept of such a God is inconsistent or incoherent; or (iii) that the existence of such a God is ruled out by evidence which is available to all, e.g. the amounts and kinds of evils in the world. Of course, the strong agnostic might be prepared to concede that it is epistemically possible that one of these atheistic claims is correct; but she holds that there is not yet conclusive reason to believe any one of them. Moreover, unlike other atheists, the strong agnostic does not subscribe to the principle that, in the absence of any positive evidence for the existence of $x$ 's, one is rationally required to believe that there are no $x$ 's. Even though the strong agnostic contends that there is currently available no good evidence for the existence of God, she holds that what is rationally required is merely refusal to assent either to the claim that God exists or to the claim that God does not exist.

A case for strong agnosticism can be constructed as follows: It seems reasonable to allow that it is at least epistemically possible that the universe was created by one or more beings -- i.e. it is not obvious that this is a claim which can simply be ruled out a priori, or on the basis of uncontroversial evidence. So, suppose that the universe was created by one or more beings. What is it reasonable to believe about such beings on the basis of the available evidence -- i.e. on the basis of what we know, or can reasonably believe, about the universe?

It seems that it would be quite rash to suppose that such beings must be omnipotent and omnisicient. True, such beings would surely have powers and knowledge which we do not have. In particular, if they created the universe ex nihilo, then they have powers which it is impossible for us to have. But what reason is there to suppose that they can do anything which it is logically possible for them to do, and that they know everything which it is logically possible for them to know? Is there any reason to suppose that one would need to know everything which it is logically possible for one to know in order for one to be able to create a universe like ours? For instance, should we suppose that the creators of the world must know everything about transfinite arithmetic? This is surely an entirely open question. Similarly, is there any reason to suppose that one would need to be able to do everything which it is logically possible for one to do in order for one to be able to create a world like ours? Should we suppose that the creators of our universe were able to create uncountably many similar worlds? Or should we suppose that this world is the only world which they had in them? Again, this looks like an entirely open question. 
It also seems that it would be very rash to suppose that such beings are omnibenevolent. Even if -- as many theists have argued -- the amounts and kinds of evil in the world are compatible with the existence of an omnibenevolent deity, it is not at all clear that this evidence does not point more strongly towards creators with an entirely different moral character. At the very least, it seems that it is no less plausible to suppose that the creators of the world have morally indifferent characters, or to suppose that the creators of the world are themselves morally evil -- things might get pretty dull in whatever realm they inhabit; and what need our suffering be to them? Of course, in the latter case, there will be problems about the amounts and kinds of good in the world -- but, even in the case in which the creators in question are omnimalevolent, it is hard to suppose that there is any more difficulty than there is for the traditional theists who attempts to deal with the problems of evil.

Similar sceptical doubts can be raised about the number, eternality and personality of these beings. However, the upshot of this enquiry is surely already clear: the available evidence certainly seems to allow many different epistemically possible creators. Perhaps it might be objected that there is evidence which has not been taken into account -- e.g. the evidence of religious experience, religious authority, revelation and scripture. However, none of this is "available evidence" -- i.e. evidence which will be recognised as such by theist and non-theist alike. In order to determine whether the evidence supports the claim that the God of traditional theism exists, we must set aside anything which could only be claimed as evidence for this God's existence by those who already believe that this God does in fact exist. Thus, e.g. one could only suppose that the Bible provides evidence of the existence of this particular God if one already believes that this God exists; one who believed, say, that the world was created by a malevolent creature would suppose that the Bible is evidence of the cunning of this being. ${ }^{2}$

But if the conclusion of the preceding paragraph is correct, then, even for those who believe that the universe has creators, a question arises, viz: in which of the possible creators ought one to believe? One might take the view that all one ought to believe is that there are creators, and leave it at that. But to take this view is to fail to believe in the God of traditional Western theology, or in any of the other epistemically possible alternatives. Moreover, this view is manifestly insufficient to sustain a religious outlook on life. At this point in the argument, it is an open question whether the creators deserve our thanks. One might be delighted with one's life no thanks to them -- so one's own happiness isn't sufficient to answer the question which attitude one ought to take. In any case, even to believe that there are creators is to believe too much -- for it is compatible with all the evidence we possess that the universe is uncreated. And indeed, to the extent that we feel impelled to believe in creators, it seems that we shall be equally impelled to believe in creators of those creators, and so on. If we are prepared to 
allow that this regress halts somewhere, then it is hard to see how we could rule out the possibility that it halts right at the beginning, i.e. with an uncreated universe.

Recently, there has been a revival of interest in teleological arguments which begin with the claim that the occurrence of life in the universe depended upon the utterly unlikely concurrence of a number of improbable events and specific values of universal parameters. ${ }^{3}$ Doesn't this data show that it is much more reasonable to suppose that the universe is the outcome of creative intelligence? No. We don't know much about the contours of broadly logical, i.e. metaphysical, space -- contours which, of course, can only be discovered $a$ posteriori -- but it seems highly implausible to suppose that ours is the only kind of universe which could support intelligent moral agents. Moreover, although we can conjecture that, as we move along certain axes in logical space, we find only universes which do not contain human beings, we can't even be sure -- given enough parameters and initial events -- that our local region of logical space isn't densely populated with universes which contain human beings. And, finally, we have little idea what kinds of intelligent moral agents there might be other than human beings, nor much idea about the conditions under which they might flourish. So: Even if we are inclined to think that our existence is an incredible stroke of luck, the postulation of creators cannot be guaranteed to explain that luck. For it would seem to be equally a matter of incredible luck that they were disposed to create our universe rather than one of the possible alternatives. Moreover -- and more importantly -- we have no idea whether ours is the only universe, and hence don't know whether it is appropriate to think that our existence is an incredible stroke of luck. Maybe there are a vast number of uncreated worlds, but ours is the only one which contains intelligent moral agents. Or maybe there are a vast number of worlds which were created by hopelessly incompetent deities. Etc. Once again, it seems that suspension of judgement is the only reasonable course.

So, in sum: the available evidence no more supports the belief that God exists than it supports belief in numerous incompatible hypotheses. But, in such circumstances, it cannot be rational to believe that God exists. On the other hand, there seems to be no obvious way of deciding whether it is more likely that the universe was created than that it was not created -- though see section four below for a discussion of one argument which might be thought to do the trick. Since the total evidence fails to support any one hypothesis more than its competitors, the only rational course is to suspend judgement. Because it seems reasonable to think that there are many ways in which the world could be uncreated, we may suppose that we are here considering all of the epistemically possible hypotheses concerning the origins of the universe.

This completes the case offered on behalf of the strong agnostic for her view that: it is neither rational to believe that God exists, nor to believe that God does not exist. The case for the 
second part of this claim may seem very weak; after all, if one is prepared to assume that the available hypotheses are all equally likely, then it seems that one is obliged to say that the probability that any particular one of them is true is almost infinitesimally small. And, in that case, isn't really true that one disbelieves the hypothesis that God exists? No; the lottery paradox shows that this can't be right. In a lottery with infinitely many tickets, there is only an infinitesimal chance that any particular ticket will win. Nonetheless, if I believe of each ticket that it won't win, then I shall be obliged to conclude that no ticket will win -- i.e. I will be obliged to believe something false. What goes for hypotheses about lottery tickets goes for cosmological hypotheses too: for any particular hypotheses among those countenanced above, I should think that it is epistemically very unlikely that the hypothesis is true; but, nonetheless, I should not believe that it is false.

There are some obvious lines of response to the outlined argument for strong agnosticism. I shall discuss three related reponses; the combined effect of these three responses is, I think, fatal.

(i) The appeals to simplicity and Ockham's Razor: The strong agnostic claims that there is no reason to prefer the hypothesis that the God of traditional Western theology exists to numerous logically incompatible hypotheses -- and, more strongly, that there is no reason to prefer any hypothesis about the causal origins of the universe to any other. However, it might be suggested by theists that this claim overlooks one significant consideration which underwrites the choice of belief in God -- namely: that the hypothesis that the God of traditional Western theology exists is the simplest hypothesis which explains the data, and that this is a reason for supposing that it is more likely to be true. ${ }^{4}$ And, similarly, it might be suggested by atheists that the strong agnostic's claim overlooks the importance of a version of Ockham's Razor according to which, in circumstances in which one lacks any evidence for an a posteriori existence proposition, one has sufficient grounds to believe the negation of that proposition. $^{5}$

There are various replies available to the strong agnostic. First, in response to the theist, she can observe that it is far from clear that the hypothesis that the God of traditional Western theology exists is the simplest hypothesis. On the one hand, some hypotheses which hold that the universe is uncreated seem no less simple. ${ }^{6}$ And, on the other hand, it is not clear that the hypothesis that the God of traditional Western theology exists is simpler than, say, one of the numerous hypotheses involving a quite powerful -- but not omniscient, quite knowledgeable - 
- but not omnipotent, morally indifferent deity. How is one to decide whether it is simpler to suppose that God is omniscient or to suppose that the creators have some -- perhaps hard to specify -- properties which fall short of omniscience? Surely the fact that the properties in question might presently be "hard to specify" dos not show, ipso facto, that the hypotheses in question are more complex -- for, in that case, our criterion of simplicity depends upon the vagaries of current notation. Yet presumably "likelihood of truth" ought not to be tied to current notation in this way. Of course, it is not here denied that there are good pragmatic reasons for using a criterion tied to the vagaries of current notation in selecting hypotheses -e.g. in the sciences. However, it will be insisted that these reasons have nothing to do with truth; indeed, it will be said that we use simplicity to choose between hypotheses precisely when we recognise that the available evidence does not allow us to discriminate between them in terms of likelihood of truth.

Perhaps the theist might reply that the simplicity of the hypothesis provides a pragmatic reason for adopting the hypothesis that the God of traditional Western theology exists. However, it is hard to see that this could be an overwhelming practical reason. For suppose we ask: what reason could we have for wanting to choose between the competing hypotheses in question? If our reason is that we think that a correct choice will be rewarded, then surely practical reason will be on the side of refusing to choose. For, no matter what our choice is, there are possible creators who will reward us for making it, possible creators who will be indifferent to our making it, possible creators who will punish us for making it, etc. The only reasonable response seems to be to forget about the whole matter, and to concentrate on something which is much more tractable -- namely, one's conduct in one's present life. And if it is objected -- as it would have been by Pascal -- that one's present life will go best if one chooses to believe in the God of traditional Western theology, quite independently of whether such a God in fact exists, then the correct thing to say is simply that this is not credible. If there is no God, then any use which is made of the mistaken belief that God exists will surely involve costs which could be avoided without giving up any of the benefits accrued. Perhaps the theist might respond with an appeal to Pascal's wager. But -- as I have argued elsewhere ${ }^{7}$ -- the strong agnostic can reasonably contend that there are infinitely many possible creators. Consequently, even if one thinks that the apparatus of decision theory can be correctly applied in cases in which there are infinite utilities, one will find that the value of the wager on God can be trumped by other considerations. And, in any case, there are many other deities whose existence would ensure an equally good outcome. So there is no escape here.

Perhaps, despite the foregoing arguments, the theist will insist that the decision to "forget about the whole matter" involves a choice which reason cannot guarantee to be correct. If it is all right to wager this way, why would it be wrong to wager on belief in the God of traditional Western theology? Well, on the one hand, the decision to "forget about the whole matter" is 
the only non-arbitrary decision to be made in the circumstances. When theoretical reason recognises that it has next to no chance of obtaining the truth, then it opts to avoid falsehood - compare the corresponding case of the lottery. And, on the other hand, there are practical reasons in favour of "forgetting about the whole matter". For, if the argument advanced by the strong agnostic is cogent, then we are all members of a community which is in the predicament that it cannot answer certain “ultimate questions” about its life. In these circumstances, surely what we owe to ourselves and to each other is to make that part of our lives of which we are certain -- and which may be the whole of our lives -- as good as possible. That end will be hindered if individuals make different wagers on the question of religious belief, as our history shows; and there is reason to suppose that it won't be furthered even in the unlikely event that we can all agree to wager on the same deity. To do anything other than "forget about the whole matter" is to give up certain goods for utterly uncertain returns. In other words: the expected value of the sceptical wager is greater than the expected value of the wager on God!

Second, in response to the atheist, the strong agnostic can insist that the principle to which the atheist appeals -- viz. that in circumstances in which one lacks any evidence for an $a$ posteriori existence proposition, one has sufficient grounds to believe the negation of that proposition -- is also refuted by the lottery paradox; this, by the way, explains why the two objections were grouped together. The problem is that, in some circumstances in which one lacks evidence, one will lack evidence for every relevant a posteriori existence proposition -but one will also know that some relevant a posteriori existence proposition(s) must be true. Thus, for example, although there is no good reason to think that there are currently intelligent beings inhabiting the fifth planet of the Vega system, the correct view to have is simply that this claim is very unlikely to be true. ${ }^{8}$

I conclude that the strong agnostic can reasonably insist that straightforward appeals to simplicity and Ockham's Razor do not defeat the case constructed in the first section of this paper. Theoretical reason cares nothing about such considerations, since it is primarily concerned with truth; and practical reason must respond to other considerations which swamp the force of such appeals.

(ii) The threat of global scepticism: A second line of response to the argument of the strong agnostic is to suggest that it proves too much. The strong agnostic relies on the claim that, when confronted with hypotheses between which the available evidence will not decide, one ought to withhold belief from each of those hypotheses. But surely this will be fatal to belief in other minds, belief in the external world, belief in the reality of the past, belief that the future will be like the past, belief in scientific theories, etc! For, in all these cases, it is 
plausible to suggest that there is no evidence which supports the commonly held views against sceptical alternatives. Consider, for example, the case of belief in scientific theories. Suppose that it turns out that there are genuinely conflicting total scientific theories which account equally well for all the evidence available to us. In that case, the considerations adduced by the strong agnostic in support of her agnosticism suggest that one ought not to believe of any particular such theory that it is true. ${ }^{9}$

Perhaps the strong agnostic can dig in her heels. One person's modus ponens is another person's modus tollens. Why not insist that, in the circumstances envisaged, there would be no point in arbitrarily believing of one of these theories that it is the one true theory. Since the theories are ex hypothesi equally empirically adequate, we should use whichever one is most convenient for practical application, chosen according to the circumstances in question. And, beyond that, we lose nothing if we simply admit our ignorance. Note, by the way, that the strong agnostic need not here take a stand on one important dispute between realists and antirealists. It may be that there is only one possible empirically adequate total scientific theory, formulable in many different notations. However, it may also be that -- among the genuinely conflicting total scientific theories which account equally well for all of the evidence available to us -- the one true theory is only distinguished by facts which are inaccessible to us. All that the strong agnostic needs is the concession that there is now no good reason to believe that the former alternative obtains. So there is no threat to the strong agnostic argument here. And nor is there any threat from actual -- as opposed to ideal -- science, for it is simply not the case that we have good reason to believe that we have ever been confronted with genuinely competing, empirically adequate, theories. The historical record suggests that we have little reason to believe that any of our theories is empirically adequate -- though it does suggest that there is good reason to suppose that later theories are more empirically adequate than their predecessors. So we don't have reason to believe that our scientific theories are true, even though we have the best possible reasons for accepting them, i.e. for relying on them in making predictions, giving explanations, etc.

Perhaps this response is not acceptable; clearly, there is room for much further debate. But, in any case, no similar moves are plausible in the remaining cases. While there is not universal agreement that there is something wrong with constructive empiricism -- and other less than robustly realist accounts of scientific theories -- there is more or less universal agreement that there is something wrong with scepticism about the external world, other minds, induction, and the past. Of course, there is little concensus about exactly where such sceptics go wrong; but it does seem plausible to think that such scepticism should be rationally avoidable. Certainly, if the strong agnostic is saddled with the claims that one ought to suspend judgement on the question whether there are other minds, that one ought to suspend judgement on the question whether the world was created just five minutes ago, that one 
ought to suspend judgement on the question whether heavy objects will fall towards the centre of the earth tomorrow, and that one ought to suspend judgement on the question whether there really are chairs, tables, and wombats, then this is good reason to think that there is something wrong with strong agnosticism. But how could the strong agnostic avoid the objectionable claims?

Perhaps like this: It is clear that there are cases -- such as lotteries -- in which the type of argument deployed by the strong agnostic is correct. In other words, in some cases in which one is confronted by a range of hypotheses between which no available considerations can decide, the reasonable thing to do is to suspend judgement. This suggests that if the sceptical conclusions are to be avoided, there must be "available considerations" which decide in favour of, e.g., the hypothesis that there really are chairs, tables, and wombats. But what could these considerations be? Well, one feature of all the sceptical hypotheses is that if one is to accept them, then one must suppose that oneself is very special. On sceptical hypotheses about other minds, one supposes that one is utterly different in kind from other apparent people. On sceptical hypotheses about the existence of chairs, tables, and wombats, one supposes that great pains have been taken to deceive one -- and, hence, one also supposes that one is utterly different in kind from other apparent people. On sceptical hypotheses about the similarity between past and future, one supposes that the time in which one's own life takes place involves a special sort of discontinuity. And on sceptical hypotheses about the reality of the past, one supposes that part of one's own life has a special status in the apparent chronicle of history. Now, the proposal which the strong agnostic wishes to make is that it is partly constitutive of reasonable belief that one does not hold beliefs which require one to suppose that one is special in the way that the sceptical hypotheses require one to believe that one is special. Moreover, this proposal does serve to draw a line between the argument defended by the strong agnostic and the sceptical conclusions; one makes no assumption that one is special -- in the way required by sceptical hypotheses -- in adopting any of the alternatives to the traditional theistic hypothesis -- and so the proposal does eliminate sceptical arguments while leaving the agnostic argument untouched.

Of course, there is an obvious problem with this line of defence -- namely, that the strong agnostic seems to have given up the idea that the only court of appeal in deciding betwen the truth of competing hypotheses is the available evidence. Why should hypotheses which require that one is special be rejected if this consideration has no bearing on the truth or falsity of those hypotheses? And, if it is constitutive of rationality that one should reject such hypotheses, then why can't the opponents of the strong agnostic insist that it is also constitutive of rationality to be moved by considerations of simplicity? Perhaps it can be conceded that there is an available position -- i.e. the view that, the alleged constitutive principle apart, the only thing to which one can appeal in deciding between hypotheses is the 
available evidence -- but it is hard to see how the position could be motivated. And, if the position can't be suitably motivated, then it seems that the argument of the strong agnostic fails. However, there may still be a plausible response available to the strong agnostic, viz. to insist that it is simply obvious that the case of cosmological hypotheses is relevantly like the case of a lottery, but relevantly unlike the cases of implausible scepticism, even though it is remarkably hard to say what these relevant respects are. In order to show that the argument of the strong agnostic is wrong, an opponent needs similarly to distinguish the case of the lottery from the sceptical cases, and then to show that cosmological hypotheses fall on the side of the sceptical cases. Even though the argument of the strong agnostic is incomplete, it surely presents a challenge which theists and atheists are obliged to meet.

(iii) The rationality of ungrounded beliefs: A third line of response can be taken to begin from a denial of the claim that there is still a remaining challenge for theists and atheists. In order to fend off the sceptical arguments, the strong agnostic either appeals to a principle which is claimed to be partly constitutive of rational belief, or else simply insists that cosmological hypotheses are relevantly like lotteries. But in neither case does the strong agnostic offer any evidence in support of these claims. Moreover, it is hard to see what form such evidence could take. But, in that case, it seems that the strong agnostic will need to insist that either the principle or the claim -- or both -- is cognitively basic -- i.e. that there is nothing further which is suitably independent to which one could appeal in order to defend them. But, if this is right, then why shouldn't a traditional theist claim that belief in the existence of God can be cognitively basic -- i.e. unsupported by any independent evidence, and yet perfectly justified, perhaps because supported by non-independent grounds?

Perhaps the strong agnostic might object that there are obvious differences between the suggested status of the principle to which she appeals and the suggested status of belief in God. In particular, the principle to which the strong agnostic appeals is intended to be a requirement on right reason; but the belief to which the theist appeals is only claimed to be rationally permitted -- i.e. the theist is not making the surely ill-advised attempt to claim that belief in God is rationally required even though there is not the slightest evidence to support that belief. Perhaps, then, it might be suggested that cognitively basic beliefs and principles must be ones which can reasonably be thought to be obligatory. More exactly: if one holds that a certain principle or belief is cognitively basic, then one must hold that any reasonable person in the same broad kind of epistemic situation in which one finds oneself would also adopt that belief or principle.

This claim has been denied. ${ }^{10}$ However, the strong agnostic might well doubt that the denial is reasonable. For consider. If one allows that certain beliefs or principles are cognitively basic, and yet also allows that it is equally permissible to adopt conflicting basic beliefs or 
principles, then surely there is nothing to sustain one's own choice of beliefs and principles. If one genuinely allows that it is equally permissible to adopt alternative basic beliefs or principles, then surely one must hold that one's own basic beliefs and principles are entirely arbitrary. But no-one can think that her basic beliefs and principles are arbitrary; for that is to throw reason to the winds. In particular, one must think that one's basic beliefs are true, and that one's basic principles are conducive to the formation of true beliefs. But basic beliefs selected arbitrarily from amongst beliefs most of which are false will almost certainly be false, and basic principles selected arbitrarily from amongst principles most of which are not conducive to the formation of true beliefs almost certainly will not be conducive to the formation of true beliefs. No-one can reasonably think that her basic beliefs and principles have been arbitrarily selected. ${ }^{11}$

One possible response to this objection is to claim that there can be theists who recognise no alternatives to their cognitively basic belief in God: surely, if there are any such people, it is rational for them to believe in God. This point can be conceded; but only because it is irrelevant. Such people, if there are any, are not sufficiently well-informed; they do not possess relevant information about at least epistemically possible alternatives to belief in God. However, if they did possess that information, they would cease to be rational if they continued to maintain that belief in God is cognitively basic. The aim of the strong agnostic is to argue that no-one who is fully appraised of the arguments developed by the strong agnostic can reasonably believe in God; hence, people who are simply ignorant of the relevant considerations cannot constitute counter-examples. And, of course, the same point applies to people who are unable to understand the arguments, or who willfully refuse to consider them, etc. People who lack reasoning skills, or who refuse to use the skills they have, cannot constitute counter-examples to the claims of the strong agnostic. ${ }^{12}$

Another possible response is to suggest that there can be theists who recognise no legitimate alternatives to their cognitively basic belief in God. The idea here is that, from within the religious life, belief in God can be seen to be well-grounded. Given the appropriate religious background, there are conditions and circumstances which “call forth” belief in God -- i.e. conditions and circumstances in which, on this view, a believer will be correctly disposed to say: God is speaking to me; God has created all this; God forgives me; etc. ${ }^{13}$ Of course, the theist recognises that there are many other possible stances which share this "self-justifying" status $^{14}$; so there is no suggestion that the grounds in question might be available even to those who do not believe. But, it will be said, while it is true that there are no reasonable or evidential considerations which will take one from an initially sceptical position to belief, and while it is also true that the grounds for religious belief -- drawn from revelation, religious experience and scripture -- are not suitably available to non-believers, nonetheless this is simply irrelvant to the question whether theistic belief is rational. What matters is that, in the 
light of the evidence as she construes it, the theist's belief that God exists is manifestly rational. Since the theist is not in the position of the non-believer, she does not share his epistemic problem -- and, indeed, need take no account of it.

The strong agnostic may object that this attitude is indefensible. Surely, if it is conceded that belief in God is just one among many possible views which shares all of the epistemic virtures of belief in God, then the maintenance of any one of those views must be entirely arbitrary. And, in that case, it cannot be rational to persist with any one of them. If there is no viewpoint-independent consideration -- i.e. consideration which is common to the range of views -- which favours the adoption of one of the views, and yet it is conceded that no view is in any way epistemically superior to any other, then it really is unreasonable to adopt any one of those views. After all, in adopting a particular view, one must suppose that that view has the fundamental merit of being true. But, if there is no further epistemic virtue which the view has, then what reason can there be for thinking that it is the one which it true? Indeed, wouldn't the adoption of one of these views -- e.g. belief in the God of traditional Western theism -- be just like the adoption of one of the sceptical hypotheses discussed earlier in that it requires an inappropriate belief that one is "special”.

I think that the strong agnostic is only partly right here. It is true that, according to the epistemological picture under discussion, epistemic agents are required to think that they are epistemically special in the following sense: any rational agent should concede that there are no suitably independent external considerations which show that her view is superior to rationally permissible alternatives. However, there is nothing wrong with this consequence of the picture -- for the only genuine alternative to the picture is, as the opponents of the strong agnostic earlier insisted, an untenable scepticism. That there are alternatives to one's own views which are, in a suitably external sense, epistemically just as good, does not give one any reason to think that the views which one has are probably false. A rational agent will persist with the views which she has until she is shown that she can improve her view by changing it.

Why then does the position of the strong agnostic have intuitive appeal? I think because of a confusion between rules of dialectical debate and epistemic principles. In debate, and hence in philosophical argument, the only considerations to which useful appeal can be made are those which are acceptable to all participants. Hence, if one supposed that the project of philosophy is to justify the view which one holds in debate, then one would need to suppose that such justification would procede from principles agreed to by all reasonable persons. But that just shows that this is a bad conception of the project of philosophy. For it is simply misguided to think that any world-view can be defended in this way by appeal to purely external considerations. $^{15}$ 
Of course, it should now be clear why I said that strong agnosticism fails because the two kinds of principles upon which it relies cannot be plausibly conjoined. On the one hand, the principle that in circumstances in which the available evidence no more -- and no less -supports $p$ than it supports logically incompatible hypotheses $p_{1}, \ldots, p_{n}, \ldots$, one ought to suspend judgement between all of the hypotheses $p, p_{1}, \ldots, p_{n}, \ldots$. is clearly correct if "the available evidence" is taken to include internal considerations, but also clearly incorrect if "the available evidence" is taken to include only external considerations. But, on the other hand, this is just to deny the second required principle, viz. that it is possible to characterise a suitable notion of evidential support which does not rely upon a relativisation to background assumptions -- theories, points of view.

In sum: strong agnosticism fails because it does not respect the tenets of methodological conservatism. There cannot be an obligation on reasonable persons to believe only what is required by suitably independent evidence -- for, under this obligation, subjects would not be able to believe all kinds of things which it is quite clear they ought to believe. Moreover, there is no way for the strong agnostic to suitably motivate her response to the threats posed by various kinds of scepticism and by the possibility of appeals to simplicity and Ockham's Razor -- for, once the demand for external evidential motivation lapses, the plausibility of the claim that these responses are externally motivated simply evaporates.

Given the strong agnosticism fails, one attracted to an agnostic position should retreat to weak agnosticism. Moreover, the reason given for the failure of strong agnosticism suggests that this retreat should be easily accomplished -- for, given the precepts of methodological conservatism to which the opponents of the strong agnostic appealed, it is surely plausible to think that there are no suitably external considerations which must lead a reasonable weak agnostic to give up her position. However, this will only be so if the precepts of methodological conservatism are acceptable -- so we shall now turn our attention to them.

The epistemological precepts under consideration has been forcefully enunciated and defended by Gilbert Harman, in his book Change In View. ${ }^{16}$ The most important principle is the Principle Of Conservatism: One is justified in continuing fully to accept something in the absence of special reason not to. An important subsidiary tenet is that one should subscribe to the Principle Of Positive Undermining -- viz. that one should stop believing that $p$ whenever one positively believes one's reasons for beliving that $p$ are no good -- but 
not to the Principle Of Negative Undermining -- viz. that one should stop believing that $p$ whenever one does not associate one's belief in $p$ with an adequate justification, either intrinsic or extrinsic. There are yet further principles -- e.g. The Principle Of Clutter Avoidance and The Interest Condition -- which form important planks in the theory, but these will not concern us here. This approach to epistemology has numerous merits, not least that it serves to defuse debates about various previously controversial issues -- e.g. debates about various kinds of philosophical scepticism. However, rather than emphasise these merits, I shall instead consider some potential difficulties.

Initially, the most plausible objection to this approach to epistemology lies in the suggestion that it conflates "internal” and "external” justification. Thus, for example, Huw Price claims that Harman fails to distinguish between "an 'external' justification of a principle or habit of belief revision, which aims to show that it is somehow useful or appropriate to conform to a certain rule; and an 'internal' justification which aims to provide the kind of reason to which an agent could actually appeal in support of an application of the principle in question.” Price then goes on to observe that "[Harman's Principle Of Conservatism] is plausible only if "justified" is taken in the external sense. Thus if we have always believed in the existence of Ralph (the Great One), our continuing to do so may well exemplify a useful habit of conservatism, painfully acquired in the evolution of the species. But when we encounter someone who believes instead in Stella (the Great One), and hence feel the need to justify our faith, our long and unblemished record gives us no reason to keep it.”"17

Various responses to this objection may be viable; I think that what should be resisted is the suggestion that, when one encounters an apparently reasonable person who holds a position which contradicts the position which one espouses, one thereby incurs an obligation to find suitably external justificatory reasons which support one's own position. Of course, one ought to have a -- possibly causal -- story about how the other person has gone wrong -- perhaps they were mislead by false testimony even though they were perfectly justified in accepting that testimony, etc. -- but there is no reason to think that this story should seem anything other than question-begging to the one with the conflicting view. Recall how difficult it has proved to find non-question-begging defences for induction. That suitably external defences seem to be unavailable does not give any of us the slightest reason to give up our inductive practices. In order to persist with one's belief in Ralph, one does not need to find reasons which would lead the previously uncommitted to believe in Ralph and not in Stella; rather, all one needs is a differential causal explanation of how the believers in Stella came to have those false beliefs -- compare the strategy, available to theists, which ascribes the error of atheists and agnostics to the effects of sin. Of course, one can't merely say: "I subscribe to the Principle of Conservatism, so I have a sufficient reason to continue to believe in Ralph”. But one can say: "Because I subscribe to the Principle of Conservatism, I hold that it is sufficent for me to find 
“internal” reasons -- i.e. reasons which, from an external standpoint, may seem to be entirely question-begging -- in order to justify my continued belief in Ralph rather than Stella.” One does not need to suppose that one's reasons are available to other points of view in order to continue to accept them as reasons.

On the basis of this rather brief discussion, I conclude that Harman's epistemological prototheory -- which is clearly closely related to the views of those theists who appeal to the proper basicality or proper unarguedness of religious beliefs -- is a very promising platform for the support of weak agnosticism. Of course, more would need to be said to persuade the unconvinced; but it is beyond the brief of the present paper to try to do so. And, in any case, by the lights of the underlying epistemological theory, there may not be any point in pressing on with an attempt to persuade the unconvinced! Such people should read this paper as an argument for a conditional thesis, viz. that by the lights of the presupposed epistemology, weak agnosticism is a defensible position.

Even those who are prepared to countenance or espouse the underlying epistemology may feel that there remains a pressing objection of principle, viz. that weak agnosticism is inconsistent in its treatment of sceptical religious hypotheses and other sceptical hypotheses. If the weak agnostic is not prepared to accept or reject the many conflicting hypotheses about the cosmological origins of the universe, why isn't she similarly prepared neither to accept nor reject conflicting hypotheses about the age of the universe, or the nature of the external world? Isn't this simply an inconistency on her part? Not at all. There is no good methodological precept which says that a rational person will have a definite opinion about everything; indeed, it seems plausible to suppose that, for any reasonable person, there will be many controversial questions about which she simply suspends judgement. And, in those cases, one correct way to represent her epistemic state is to claim that she is unable to decide between a range of competing hypotheses. Of course, there may be costs to explicit suspensions of judgement, in the form of the complexity of the representations involved; but these costs are traded against what will seem to be improved prospects of avoiding error, etc.

\section{4}

Despite the argument of the preceding section, there are some objections to weak agnosticism which remain to be discussed. In particular, there are three objections which suggest that weak agnosticism is actually inconsistent or, strictly speaking, unbelievable. I shall consider these objections in turn. 
(i) The Deistic alternative: There is an argument, inspired by an argument which Peter Forrest uses against David Lewis' modal realism, which suggests that it is more reasonable to believe that there are creators than it is to believe that the world is uncreated. ${ }^{18}$ Of course, the purported upshot of this argument is only that the weak agnostic should retreat to deism -- i.e. it is not suggested that this argument could motivate a shift to theism: Corresponding to any uncreated world, there are infinitely many created worlds, each with a different creator. Consequently, the odds are infinitely in favour of the hypothesis that our world is created; it is almost vanishingly unlikely that our world was not created. So we ought to believe that the world has creators.

David Lewis has suggested one way to respond to the above argument -- namely, to claim that it can be paralleled to its discredit. ${ }^{19}$ On one way of partitioning the integers, there are infinitely many non-prime numbers for each prime number. Consequently -- following the above argument -- if an integer is chosen at random I ought to believe that it is non-prime. However, on another way of partitioning the integers, there are infinitely many prime numbers corresponding to each non-prime number. Consequently -- following the above argument -- if a number is chosen at random, I ought to believe that it is prime. So, I have two equally good arguments which lead to the conclusion that, if a number is chosen at random, I ought to believe both that it will be prime and that it will be non-prime. Clearly, then, both arguments are to be rejected, along with the argument which purports to make trouble for agnosticism.

Lewis’ objection refutes the argument which I initially gave: the only probabilistic arguments which one can make about infinite cases are ones in which one has no relevant choices to make about the partitioning of the probability space. ${ }^{20}$ However, suppose that I had argued as follows: I have no idea whether or not the world which we actually inhabit was created. However, there are infinitely many worlds which differ from it at most in that they have creators, different from the creators, if any, which it actually has -- and there is only one world which differs from it at most in having no creators. So, among the relevant possibilities, there are infinitely many worlds which have creators, and only one which is uncreated. Consequently, there is next to no chance that the world which we actually inhabit is uncreated. In this case, Lewis' response is not available. This argument is solely about the actual world and worlds relevantly like it, not about all the possible worlds which there are. Consequently, there is no partition which can be gerrymandered by a Cantorian argument. So if this argument is to be defeated, some other response is required.

The new argument requires the assumption that there is only one way in which a world like ours could be uncreated. But -- as I noted earlier -- an agnostic will not be prepared to grant this assumption. She will say that, for all she has good reason to believe, there may be 
infinitely many different ways in which an uncreated world can arise. Perhaps worlds are created in pairs, or triples, or quadruples, or etc. Perhaps worlds are randomly distributed -like raisins in a plum-pudding -- throughout some higher-dimensional space in which they arise as the result of some acausal process which occurs in that space. Etc. Since the agnostic sees no reason to think that it is no more likely that the world is uncreated than it is that the world was created according to one particular hypothesis about that act of creation, she has no reason to accept the modified version of Forrest's argument. ${ }^{21}$ Agnostics can reasonably resist deism.

(ii) Proofs and other evidence: There are theists and atheists who will continue to insist that weak agnosticism is unreasonable because the existence -- or non-existence -- of God can be demonstrated by arguments which appeal only to uncontroversial evidence. Thus, for example, there are theists who maintain that there are rationally compelling ontological, and/or cosmological, and/or teleological, and/or moral, and/or other arguments which establish the conclusion that God exists; and there are atheists who maintain that there are rationally compelling ontological, and/or moral, and/or other arguments which establish the conclusion that God does not exist.

I think that such theists and atheists are mistaken. While they may be entirely within their rights to suppose that the arguments which they defend are sound, I do not think that they have any reason to suppose that their arguments are rationally compelling -- i.e. that they provide reasonable opponents with compelling internal reasons to change their views. Of course, some will find this contention controversial -- but I cannot hope to provide a detailed defence here. Perhaps it is worth making the following point. It surely should be granted that, at least prima facie, there can be reasonable theists, atheists, and agnostics -- for, after all, there are undeniably sensitive, thoughtful and intelligent people who fall into all three camps. Of course, it could conceivably turn out that, e.g., there can only be reasonable agnostics in that undemanding sense of "reasonable” in which reasonable persons can hold unobviously contradictory, or unobviously unnecessarily complex, or unobviously unnecessarily explanatorily weak views, etc. But it seems to me to be clearly absurd to suppose that there are currently available arguments which should show, to the satisfaction of all, that members of two of the camps have views which are unobviously contradictory, or unobviously unnecessarily complex, or unobviously explanatorily weak, etc. Members of each of the camps may have causal hypotheses which explain how their opponents come to possess false views; but these hypotheses ought not do anything to impugn the rationality of the maintenance of those views.

(iii) The problem of other attitudes:Some people may be inclined to object that weak 
agnosticism is unliveable. Could one really carry on the projects of a normal life if one were not prepared to rule out, e.g., the hypothesis that the world is the product of a malevolent deity? Wouldn't doubts about the value and meaning of life cripple one's ordinary conduct?

I don't see why. Earlier, I had my strong agnostic claim that the only reasonable thing to do in the face of such worries is to forget about them. This seems right. It is a psychological question -- a matter of temperament -- which decides whether one could be a weak agnostic. Why shouldn't one think that value is there to be created or pursued regardless of the truth of cosmological hypotheses? Perhaps there will be a nice or nasty surprise later on; and perhaps not. Perhaps there is much more to the universe than meets the non-metaphysical, nontheological eye; but, then again, perhaps not. What good could possibly be served by worrying about these possibilities now?

Perhaps this response is unconvincing. Certainly, I concede that more should be said. Perhaps, when that more is said, I shall have been forced to shift ground to a fallibilist atheism -- i.e. to a position which treats the alternative cosmological hypotheses as definitely ruled out, but which leaves room for a higher-order concession of the possibility of epistemic error -- c.f. the "paradox of the preface". However, for now, it certainly seems to me that weak agnosticism remains a liveable option. 
${ }^{1}$ This paper began life as an ill-advised attempt to defend strong agnosticism. In this form, it was read to a session of the AAP in Brisbane in 1992, and to a colloquium in Wollongong. I am grateful to Fred Kroon, David Lewis, Peter Forrest, Scott Shalkowski, Joe Mintoff, and others, for convincing me that the position which I had endeavoured to defend was hopeless.

${ }^{2}$ As a reader for the journal kindly pointed out to me, there is a sense in which everyone can admit that religious experiences occur: for people do report having experiences which they take to be perceptions of God. But then, won't the acceptance of some kind of principle of credulity require one to regard these reports as prima facie evidence that such people have veridical perceptions of God? No. The reported content of these experiences is compatible with ever so many hypotheses about the nature of the creators of the world, including hypotheses involving neglectful or deceptive creators, and hypotheses on which there are no creators. Hence, all that a reasonable principle of credulity could require is that one accept that such people do have experiences with the reported content; that these people take the content of these experiences to be experiences of a particular deity should not provide one with any reason to suppose that the experiences really are of that deity. Indeed, more strongly, one could not take these experiences to be of a particular deity unless one had come to believe in the existence of that deity. (It should also be noted that principles of credulity must be carefully constrained: reports of experiences of alien spacecraft landing in suburban backyards surely should not be taken to constitute even prima facie evidence that there have been alien spacecraft landing in suburban backyards.)

${ }^{3}$ See, for example, John Leslie “Modern Cosmology And The Creation Of Life” in McMullin, (ed.) Evolution And Creation. Leslie has discussed these issues in numerous other publications. 
${ }^{4}$ This line of defence is inspired by the work of Richard Swinburne. See The Existence Of God, Oxford: Oxford University Press, 1979, especially pp.53-57

${ }^{5}$ See Robert McLaughlin (1984) “Necessary Agnosticism?” Analysis 44, pp.198-202.

${ }^{6}$ This point has been well-argued by John Mackie. See The Miracle Of Theism Oxford: Oxford University Press, 1982, especially pp.100-101.

7“On Rescher On Pascal’s Wager” International Journal For Philosophy Of Religion 30, 1990, pp.159-168

${ }^{8}$ Robinson, op. cit, writes: “ 'A three-headed hippogriff is alive and well right now on the fifth planet of the Vega system.’ If I followed this claim with the frank admission that I had no grounds at all for it, you might be inclined to reject it out of hand.” (p.198) The strong agnostic concedes that the admission that one has no grounds for one's assertion would remove any reason for others to accept what one says -- but this is not to concede that it gives those others reason to positively disbelieve it. Of course, the others might well have good independent reasons for thinking that the claim in question is very unlikely to be true -- but that is a different issue.

${ }^{9}$ This line of response is inspired by the early writings of Alvin Plantinga. See, especially, God And Other Minds Ithaca: Cornell University Press, 1967.

${ }^{10}$ See, e.g., Plantinga, A. "Reason And Belief In God” at p.77; and Wolterstorff, N. “Can Belief In God Be Rational If It Has No Foundations?”, especially at pp.176ff. Both of these papers are in Plantinga, A. and Wolterstorff, N. (eds.) (1983) Faith And Rationality: Reason And Belief In God Notre Dame: Notre Dame University Press. 
${ }^{11}$ The strong agnostic should probably add a qualification here. If one were first-personally dissociated from certain beliefs, then it might be possible for one to think that those beliefs had been arbitrarily selected. Moreover, there might be a thin sense of "rational” in which such beliefs could nonetheless be rational. However, the crucial point would still remain: One could not give unreserved first-personal endorsement to such beliefs. In a suitably thick sense of "rational”, beliefs which cannot be first-personally endorsed are not rational. See Robert Dunn “Attitudes, Agency, And First-Personality” (forthcoming).

${ }^{12}$ Wolterstorff, op. cit. makes much of the points dismissed in this paragraph: see, especially, p.155.

${ }^{13}$ See, e.g., William Alston (1983) “Christian Experience And Christian Belief” in Plantinga and Wolterstorff, op. cit, at pp.104-105.

${ }^{14}$ Consider, for example, belief in a morally deficient deity, God*, who doesn’t care for us much at all -- there are other worlds which she created which she likes much better -- but who nonetheless presents herself to people in the guise of an omnibenevolent being. On this view -- which might well seem better able than orthodox theism to explain the amounts and kinds of evils in the world -- conditions and circumstances will call forth certain beliefs: God* is speaking to me; God* has created all this; God* is trying to convince me that she cares for me; etc. From within this view, belief in God* will seem to be just as well-grounded as belief in God seems from the viewpoint of the orthodox theist.

${ }^{15}$ Perhaps an opponent might dig in her heels, and insist that her world is the only reasonable world-view. Even if she were right, this would be a pointless thing to say; her opponents would surely feel themselves equally entitled to make the same kind of claim about themselves. Two possibilities seem to arise: (i) the parties to the debate simply agree to differ, but each insists in her heart that she alone is rational; (ii) the parties agree to differ, but each 
alone insists that she is right (or more nearly right). To me, it seems clear that the second outcome is preferable.

${ }^{16}$ Gilbert Harman (1986) Change In View: Principles Of Reasoning Cambridge, MA: M.I.T. Press (Bradford Books)

${ }^{17}$ Huw Price (1988) “Review Of Change In View” Philosophical Books 29, pp.38-41, at pp.38-39.

${ }^{18}$ See “Occam’s Razor And Possible Worlds” Monist 65, 1982, pp.456-464

${ }^{19}$ On The Plurality Of Worlds Oxford: Basil Blackwell, 1986, at pp.119-121

${ }^{20}$ Consider the following case, which I owe to David Lewis: A fair die is to be tossed infinitely many times. You are to be assigned one toss; you are then to estimate the chance that it is a six. Why should you not reason as follows: Whichever toss I am allotted, the chance that I shall get a six is one-sixth. So I know already that the chance that I get a six is one-sixth. Answer: No reason at all. The choice of a partition of the probability space must respect the fact that you will first be assigned a toss. Partitions which combine outcomes from different tosses are irrelevant, since they fail to respect this fact. However, in the arguments about prime numbers and creators, there is no relevant fact which only one of the partitions manages to respect.

Perhaps it might be objected that the argument about prime numbers fails to take into account the way in which we grasp the natural numbers, viz. according to the standard ordering: 1,2 , $3, . .$. Isn't this a reason for saying that, really, we ought to think it vanishingly unlikely that a number chosen at random will be prime? No: if a natural number really is chosen at random -say, by an omnipotent and omniscient deity -- then the argument given by Lewis is correct. Of 
course, it is impossible for any of us to make a genuinely random choice from amongst all of the natural numbers -- but so what?

${ }^{21}$ It may be worth noting that Lewis can make a similar response to Forrest. Forrest's argument is as follows: There are infinitely many worlds which differ from the actual world at most in that they have epiphenomenal stuff in some places and not in others, but only one world which differs from the actual world at most in that there is no epiphenomenal stuff anywhere. So we should believe that it is overwhelmingly likely that our world contains epiphenomenal stuff. Now, Lewis allows that, for all he knows, there may be qualitatively indistinguishable worlds. But, if there are infinitely many worlds which are qualitiatively indistinguishable from a world which differs at most from the actual world in that it has no epiphenomenal stuff, then Forrest's argument won't work. So Lewis can say: Sure, for all we know, there might be epiphenomenal stuff; but then again, there might be infinitely many worlds which are qualitatively indistinguishable from a world which differs at most from the actual world in that it has no epiphenomenal stuff. There is no obligation to accept the premise which is required by Forrest's argument. (Note, by the way, that it simply does not follow from this response that a modal realist ought to believe either that there is epiphenomenal stuff or else that there are infinitely many worlds which are qualitaitively indistinguishable from a world which differs at most from the actual world in that it has no epiphenomenal stuff anywhere.) 